\section{Evaluation of head and neck cancer knowledge among the at-risk population of Karachi, Pakistan: a cross-sectional survey}

Evaluation of $\mathrm{HNC}$ knowledge

Zainab Mohsin

Department of Internal Medicine, Dow University of Health Sciences, Karachi, Pakistan

Arisha Faiq and Tahira Naqvi

Dr Ruth KM Pfau Civil Hospital Karachi, Karachi, Pakistan

Sameen Rehman

Dow University of Health Sciences, Karachi, Pakistan, and

Saffia Imtiaz Ahmed, Khadija Farrukh, Faiza Siddiqui,

Arifa Ali Asghar and Murk Lakhani

Dr Ruth KM Pfau Civil Hospital Karachi, Karachi, Pakistan
Received 25 June 2020 Revised 3 September 2020 8 October 2020

Accepted 15 October 2020

\begin{abstract}
Purpose - The purpose of this study was to assess the knowledge of head and neck cancers (HNCs), their risk factors, signs and symptoms among the general public of Karachi, Pakistan.

Design/methodology/approach - Initially, 503 individuals were approached for data collection, out of which 404 fit the inclusion criteria (response rate $=80.03 \%$ ). Nonprobability convenience sampling was utilized to select participants who fell under the age group of 15-60 years, barring the fields of Bachelor of Medicine and Bachelors of Surgery (MBBS) and Bachelors of Dentistry (BDS). Knowledge was evaluated by a 9item questionnaire, the scores of which yielded the following interpretations: No (0), low (1-3), moderate (4-6) and high (7-9) knowledge.

Findings - Of the 404 participants who completed the questionnaire, 357 (88.4\%) participants claimed to be aware of HNC. The HNC knowledge scores had a statistical relevance with socioeconomic status $(\phi=<0.01)$ and level of education $(\phi=0.02)$. Most participants recognized a "lump or swelling in the throat" $(87.1 \%)$ as the most common symptom, followed by "bleeding in mouth or throat" $(84.7 \%)$. Surprisingly, $75.25 \%$ of participants thought HNCs were inclusive of brain cancer.

Originality/value - Overall, knowledge of HNCs among the general public of Karachi surpasses the knowledge in other regions around the world. Our study demonstrated that people indulge in unhealthy habits despite having sufficient knowledge and this warrants prompt interventions and counseling of the people.
\end{abstract}

Keywords Head and neck cancer, Human papillomavirus, Sunlight exposure, Lip cancer, Pakistan

Paper type Research paper

(c) Zainab Mohsin, Arisha Faiq, Tahira Naqvi, Sameen Rehman, Saffia Imtiaz Ahmed, Khadija Farrukh, Faiza Siddiqui, Arifa Ali Asghar and Murk Lakhani. Published in Journal of Health Research. Published by Emerald Publishing Limited. This article is published under the Creative Commons Attribution (CC BY 4.0) licence. Anyone may reproduce, distribute, translate and create derivative works of this article (for both commercial and non-commercial purposes), subject to full attribution to the original publication and authors. The full terms of this licence may be seen at http://creativecommons.org/licences/by/4.0/ legalcode

The authors thank all participants for their contribution in completing the questionnaires. The authors are also grateful to all the authors for their effort and co-operation.

Funding: This research was not funded by any organization or institution. 
JHR

36,4

726

\section{Introduction}

Head and neck cancers (HNCs) refer to a group of benign and malignant neoplastic lesions that affect the upper aero-digestive tract, namely the nasopharynx, hypopharynx, oropharynx, lip, oral cavity and larynx. The most pervasive variety of HNC, squamous cell carcinoma, is documented to be the culprit in $90 \%$ of the cases and culminates in a 3-year survival rate of about $57 \%$ in smokers [1]. Globally, $\mathrm{HNC}$ is ranked sixth among all cancers in terms of incidence, with approximately 630,000 new patients per year and causes more than 350,000 deaths annually. Epidemiological reviews of $\mathrm{HNC}$ across Pakistan shows a marked incidence, being $21 \%$ in males and $11 \%$ in females [2]. Oral cancer is the second most common malignancy in Pakistan after lung cancer [3].

The risk factors leading to this deadly malady are smoking and undue consumption of alcohol, tobacco, betel nut and betel quid. An epidemiological study conducted amongst the citizens of Pakistan revealed the percentage contribution of the components to the development of HNCs; yielding a risk of $66.8 \%, 42.8 \%$ and $75 \%$ due to smoking, alcohol and betel nut respectively. Smoking, however, was found to be the most carcinogenic of all $[4,5]$. Moreover, the stage of disease at the time of diagnosis was found to have a grave impact on the survival rate; in stages I and II, a $60 \%$ to $95 \%$ cure is achieved with local resection alone, while advanced stages have a risk of greater than $50 \%$ chance of recurrence and metastasis [6]. Therefore, early detection of HNCs is paramount for a healthier prognosis [7]. Unfortunately in the year 2008 alone, 260,000 cases of HNC were diagnosed, with Asia having the highest prevalence of $\mathrm{HNC}[8]$.

It is unfortunate that Pakistan has been unable to meet the specifications of the nation's general population-based cancer registry for its most prevalent carcinomas. The available epidemiological data regarding HNCs are based on reports narrated by only a handful of registries [9]. Taking this into consideration, the screening and treatment collectively produce good outcomes for some cancers; the most suitable option in most other cases is primary prevention and lifestyle modifications, even within the developed nations. Thus, owing to the preventable nature and superior prognostic outcomes of HNCs, by avoidance of risk factors and early detection, respectively, and their dependence on public understanding of the disease, this study was engineered to evaluate the baseline awareness and knowledge regarding $\mathrm{HNC}$, risk factors, symptomatology, prophylactic and curative measures of $\mathrm{HNCs}$ amongst the public of Karachi, Pakistan.

\section{Methods}

\section{Survey design and participants}

A group of medical students from the Dow University of Health Sciences (DUHS) conducted a cross-sectional study over the course of five months from 2019 to 2020 (September till January). Students or graduates affiliated with the educational field of Bachelor of Medicine and Bachelor of Surgery (MBBS) or Bachelors of Dentistry (BDS) were excluded; however, all other medical fields such as Nursing, Doctor of Pharmacy were not exempted. The study targeted individuals between the age ranges of 15 to 60 years old. No discrimination based on gender, race, socioeconomic status, or religion was taken into consideration. The sample size was calculated to be 384 with an anticipated frequency of $50 \%$, confidence level of $95 \%$ and absolute precision of 5\%, via Open Epi version 3.01 (openepi.com).

\section{Data collection}

A pilot study of 20 responses was initially carried out in Karachi, and two proficient doctors reviewed the questionnaire to foolproof the study; since no changes were made in the prototype, the pilot study's responses were included in the original study. A total of 503 
individuals were approached for interviews and questionnaire filling; however, 71 refused to partake in the study, and 28 left with an incomplete questionnaire, yielding a cooperation rate of $80.3 \%$. The incomplete questionnaires were not considered. The questionnaire was selfadministered to the literate population, which established the reliability of the questionnaire; whilst interviews were conducted for the illiterate individuals by the authors. For people who were not well versed in English, an Urdu translation was available. To remove interviewer bias, the questionnaire was pre-coded and thoroughly explained to all interviewers for articulate and professional communication. The interviews were conducted at markets and hospitals; on average, one interview lasted approximately 20 min. Questionnaires were also explained to all the participants who agreed to fill out the questionnaire and were offered further assistance if needed by the principal investigator. Nonprobability convenience sampling was employed, and no imputation was exercised.

\section{Questionnaire details}

The questionnaire was divided into three sections. The first section addressed the demographics such as gender, age, occupation, marital status, level and field of education, family income and residential area. The second section inquired about the partakers' smoking habits, alcohol intake, daily sunlight exposure and family history of HNCs. Respondents were also asked if they had any prior information regarding $\mathrm{HNC}$ and were instructed to judge their own knowledge by ticking the options: "not at all", "very", "somewhat" and "extremely knowledgeable". The third section comprised of questions to evaluate participants' knowledge of risk factors, symptoms, vulnerable gender and ages, sites pervaded management and life expectancy following diagnosis. Further questions assessing knowledge on HPV, its existence as a risk factor and its available vaccination, were also asked in this section.

\section{Knowledge assessment}

Knowledge was further gauged based on "Knowledge calculation" i.e. the assessment of participants' knowledge of HNCs by a 9-item questionnaire. Positive responses (Yes) were awarded one score and negative responses (No) were awarded zero, yielding a minimum and maximum possible score of 0 and 9 respectively. Based on this, a score of zero was interpreted as "no knowledge", 1-3 as "low knowledge" , 4-6 as "moderate knowledge" and 7-9 as "high knowledge". Awareness refers to the acknowledgment of disease and knowledge refers to the accuracy and precision of information and facts regarding the disease.

\section{Data analysis}

Data were entered and tests were run using Statistical Package for Social Sciences (SPSS) version 24.0 (IBM Corp., Armonk New York). Categorical variables were tested for the association through Pearson's Chi-square test, whereas the significance of the association between categorical and continuous variables was checked via Single Sample $t$-Test and Oneway ANOVA. Associations were considered significant in accordance with a p-value of less than 0.05. Binomial logistic regression analysis was used to identify associations of risk factors with sociodemographic factors.

\section{Ethical considerations}

The study received approval from the Dow University of Health Sciences (DUHS) International Review Board (IRB). However, it met the exemption criteria, and no IRB code was assigned for the research. In addition to this, full considerations were made to protect the

\section{Evaluation of $\mathrm{HNC}$ knowledge}


JHR 36,4

728 privacy and confidentiality of the participants. A written and informed consent was sought from the volunteers, prior to the survey.

\section{Results}

A total of 404 participants were included in this study, the majority of whom were females $(n=267,66.1 \%)$. The mean age (SD; range) of the participants was $26.6(10.46 ; 15-78)$ years and more than half of them had attended college $(n=308,76.2 \%)$, while $123(30.4 \%)$ were married. In total, $51(12.6 \%)$ were current or former smokers and a small subgroup $(n=22$, $5.4 \%$ ) had a family history of HNC. Table 1 summarizes sociodemographic characteristics.

\section{Knowledge assessment}

Altogether, $357(88.4 \%)$ participants were found to be aware of HNCs. The estimation of knowledge based on scores showed that $1.5 \%(n=6), 25 \%(n=101)$ and $61.9 \%(n=250)$ people had high, moderate and low knowledge, respectively. Only $1.7 \%$ of females and $0.7 \%$

\begin{tabular}{|c|c|c|c|}
\hline Variables & $n(\%)$ & $F$-value or $t$ statistic ${ }^{\mathrm{a}}$ & $p$-value $^{\mathrm{b}}$ \\
\hline $\begin{array}{l}\text { Sex } \\
\text { Male } \\
\text { Female }\end{array}$ & $\begin{array}{c}137 \\
267(66.1)\end{array}$ & -1.53 & 0.126 \\
\hline $\begin{array}{l}\text { Age group (yrs) } \\
15-25 \\
26-35 \\
36-50 \\
\text { Above } 50\end{array}$ & $\begin{array}{r}278(68.8) \\
74(18.3) \\
30(7.4) \\
22(5.4)\end{array}$ & 1.94 & 0.13 \\
\hline $\begin{array}{l}\text { Marital status } \\
\text { Married } \\
\text { Not married }\end{array}$ & $\begin{array}{l}123(30.4) \\
281(69.6)\end{array}$ & 1.05 & 0.29 \\
\hline $\begin{array}{l}\text { Level of education } \\
\text { No education } \\
\text { Less than high school } \\
\text { High school graduate } \\
\text { Bachelor } \\
\text { Masters } \\
\text { Doctorial }\end{array}$ & $\begin{array}{r}7(1.7) \\
19(4.7) \\
70(17.3) \\
215(53.2) \\
86(21.3) \\
7(1.7)\end{array}$ & 5.65 & $<0.01$ \\
\hline $\begin{array}{l}\text { Socioeconomic status } \\
\text { Lower class } \\
\text { Lower-middle class } \\
\text { Upper class } \\
\text { Upper-middle class }\end{array}$ & $\begin{array}{c}22(5.4) \\
91(22.5) \\
8(2) \\
283(70)\end{array}$ & 3.24 & 0.02 \\
\hline $\begin{array}{l}\text { Smoking/tobacco } \\
\text { Current user } \\
\text { Not current user } \\
\text { Former user }\end{array}$ & $\begin{array}{r}30(7.4) \\
353(87.4) \\
21(5.2)\end{array}$ & 1.13 & 0.32 \\
\hline $\begin{array}{l}\text { Alcohol } \\
\text { Users } \\
\text { Non-users }\end{array}$ & $\begin{array}{r}2(0.5) \\
402(99.5)\end{array}$ & -0.54 & 0.59 \\
\hline
\end{tabular}

Table 1.

Bivariate analysis between head and neck cancers' knowledge scores and demographic characteristics of population $(n=404)$ 
of males exhibited high knowledge. The doctoral and illiterate participants $(71.4 \%)$ were found to have significantly moderate knowledge, $p=0.004$ and $p=0.001$ respectively. Among moderate knowledge participants, $10.9 \%$ belonged to the lower and lower-middle socioeconomic class each, $75.2 \%$ to the upper-middle class and $3 \%$ to the upper class and $84.2 \%$ were non-smokers. However, current smokers were less likely to fall in the moderate knowledge category $(\phi=0.049)$. Of note, $56.7 \%$ current smokers and $76.2 \%$ former users revealed low knowledge. Amid those who belonged to the upper socioeconomic class, $37.5 \%$ displayed moderate knowledge, likewise, people belonging to the lower-middle class had significantly low $(\phi=0.002)$ and moderate knowledge $(p=0.001)$, while people who belonged to the upper-middle class had low knowledge $(p=0.024)$. The lower class were likely to have significantly moderate knowledge $(\phi=0.005)$. The two extremes of age groups i.e. $15-25$ and 50-78 were significantly associated with moderate knowledge $(\phi=0.02$ for both). Moderate knowledge was also significantly associated with marital status and family history $(p=0.04, p=0.02)$.

The mean $\pm \mathrm{SD}$ of the HNC knowledge score was $1.14 \pm 1.18$. The majority $(n=318$, $78.7 \%$ ) reported themselves as "not at all" or "not very" knowledgeable about HNC. More than half $(n=219,54.2 \%)$ mentioned social media as a source of knowledge, and nearly a quarter $(n=99,24.5 \%)$ correctly identified oral cavity and neck as the most common site of HNC. "Males are more prone to develop HNC", was suggested by $115(28.5 \%)$. Conforming to this low knowledge, only $15.1 \%$ considered the elderly ( $>50$ years old) were more susceptible to develop HNC. A pessimistic ideology was observed concerning the survival of HNC patients since only $12.1 \%$ of participants believed that it has a good survival rate, further elucidated by the fact that only $8.4 \%$ believed the life expectancy of these patients to be more than 5 years (Table 2). A large proportion $(70.3 \%$ ) demonstrated cognizance toward an early diagnosis to have better survival rates and $76 \%$ postulated that lifestyle changes such as abstaining from smoking, alcohol, etc. could reduce the risk of HNC.

Those who had prior awareness of HNC scored higher on questions pertaining to knowledge $(\phi=0.001)$ and when assessed individually were significantly associated with high knowledge $(p=0.02)$. Participants indulging in limited sun exposure significantly identified sun exposure as a risk factor $(\phi=0.03)$. Surprisingly, $75.25 \%$ of participants thought brain cancer to be a subcategory of HNCs, as demonstrated in Figure 1.

\section{Identification of risk factors and symptoms}

A list of 12 risk factors was included in our survey and each participant was asked if they considered them a predisposing factor for $\mathrm{HNC}$ or not. $88.4 \%$ of participants selected smoking as a risk factor while long sun exposure remained the least selected answer $(45.8 \%)$. A summary of the perceived risk factors is given in Figure 2. Non-smokers outnumbered smokers in identifying smoking and alcohol as risk factors $(p=0.005,0.05)$. Participants belonging to the upper socioeconomic class had a better idea of the hazards of long sun exposure in relation to HNC $(p=0.05)$. Additionally, they also knew that HPV can cause throat cancer besides cervical cancer $(\phi=0.03)$, however, no significant association was found between college students and identification of HPV as a risk factor $(\phi=0.373)$. Identification of symptoms varied among participants $(49.2 \%-87.1 \%)$, with the most recognized symptom being "lump or swelling in the throat" ( $87.1 \%$ ) followed by "bleeding in mouth or throat" $(84.7 \%)$. A list of perceived symptoms is given below in Figure 3 .

\section{Predictor variables}

In the binomial regression model (Table 3), socioeconomic class, marital status and high level of education (postgraduate) were significantly associated with the identification of risk factors. Married individuals and those belonging to the upper-middle class were less likely to 


Questions $\operatorname{High} n=6$
Have you heard about the human Papillomavirus?
Yes

High $n=6$

Moderate $n=101$

Low $n=250$

Yes

6
0

32

No

69

Do you know that besides cervical cancer it can also cause head and neck cancer?

\section{0}

Yes

6

19

82

No

0

249

Do you know if there is a vaccine against human Papillomavirus?

Yes

5

22

79

No

1

What is the most common site of head and neck cancer?

Oral cavity, neck and larynx

Salivary glands, lips

Ear and nose

6

0

Brain

I don't know

0

0

0

Which gender is more prone to develop head and neck cancer?

Male

$5 \quad 65 \quad 45$

Female

0

Both

I don't know

0

Which age group is more prone to develop head and neck cancer? $<30$ years

$30-50$ years

$>50$ years

1

3

I don't know

2

What do you think is the life expectancy of head and neck cancer?

$<3$ years

3-5 years

1

$>5$ years

I don't know

3

2

0

Do you think early diagnosis can improve survival?

$\begin{array}{ll}\text { Yes } & 6 \\ \text { No } & 0 \\ \text { I don't know } & 0\end{array}$

Table 2.

Do you think lifestyle changes can prevent head and neck cancer?

Responses to questions Yes

identify family history as a risk factor when compared to single (OR $=0.5 ; 95 \% \mathrm{CI} 0.25-1.0)$ and upper-class population ( $\mathrm{OR}=0.17 ; 95 \%$ CI 0.04-0.75), respectively. Participants with a bachelor or lower degree of education were less likely to identify radiation risk as compared to postgraduates $(\mathrm{OR}=0.52 ; 95 \% \mathrm{CI} 0.29-0.94)$.

\section{Discussion}

To the best of our knowledge, no previous studies primarily focused on evaluating public knowledge of HNCs have been conducted in Karachi. Reports, however, have indicated that in 


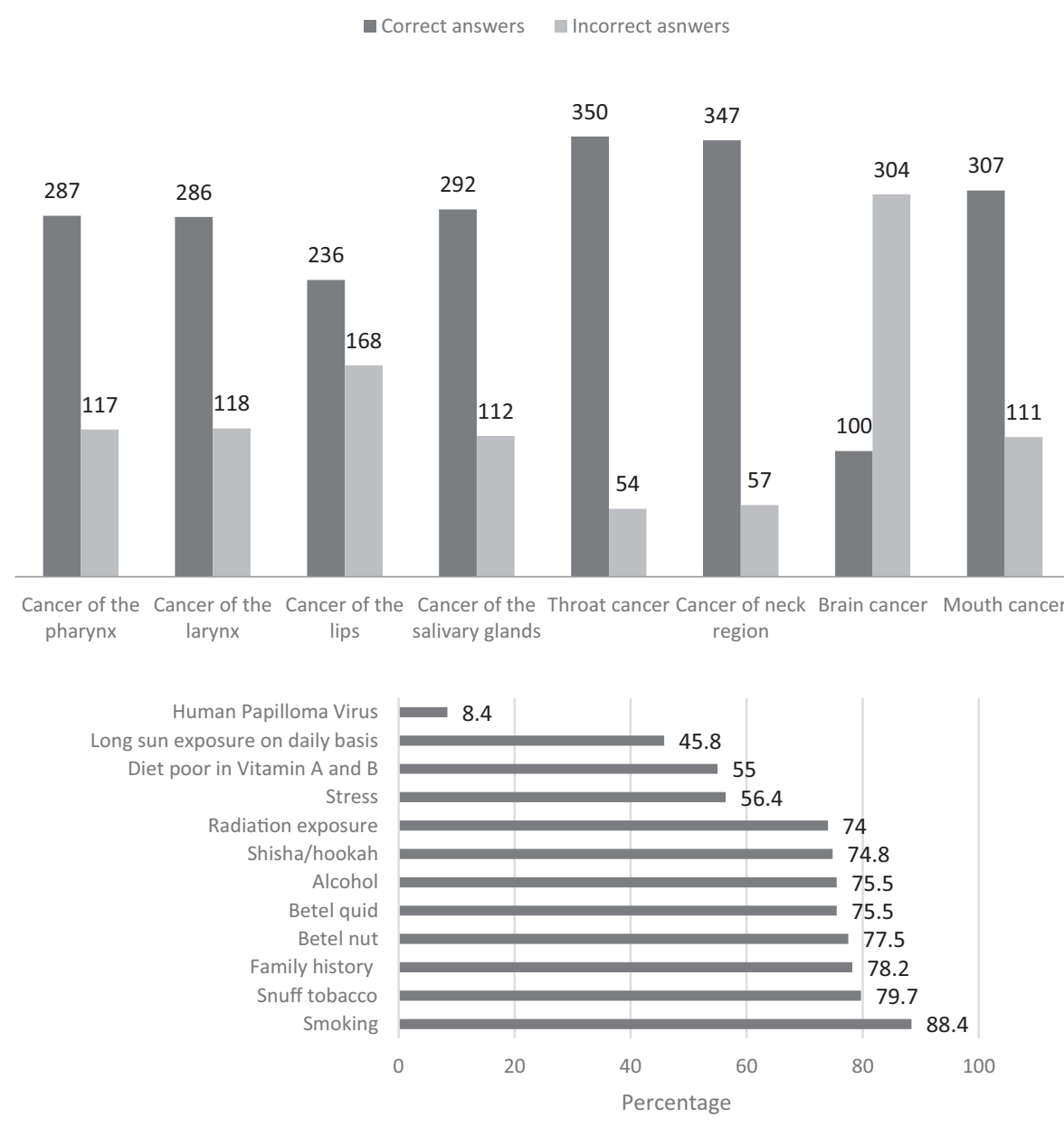
Evaluation of $\mathrm{HNC}$ knowledge

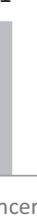

Cancer of the Cancer of the Cancer of the Cancer of the Throat cancer Cancer of neck Brain cancer Mouth cancer pharynx larynx lips salivary glands region

Figure 1.

Responses to the question "which cancers do you think are included in head and neck cancers?"

Figure 2.

Percentage of identification of risk factors of head and neck cancer No $\square$ Yes

Difficulty on swallowing Pain on swallowing Jaw pain Headache Sore throat Seizures or fits

Lump or swelling in the throat Non-healing red or white mouth sores Bleeding in mouth or throat Hoarseness
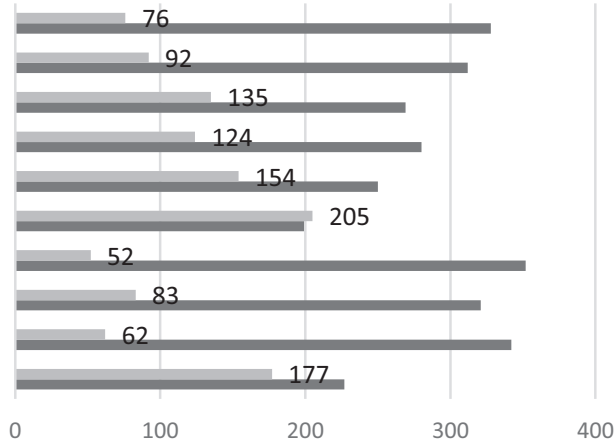

Frequency

Figure 3.

Responses to the question "what symptoms do you think are included in head and neck cancers?" 
JHR

732

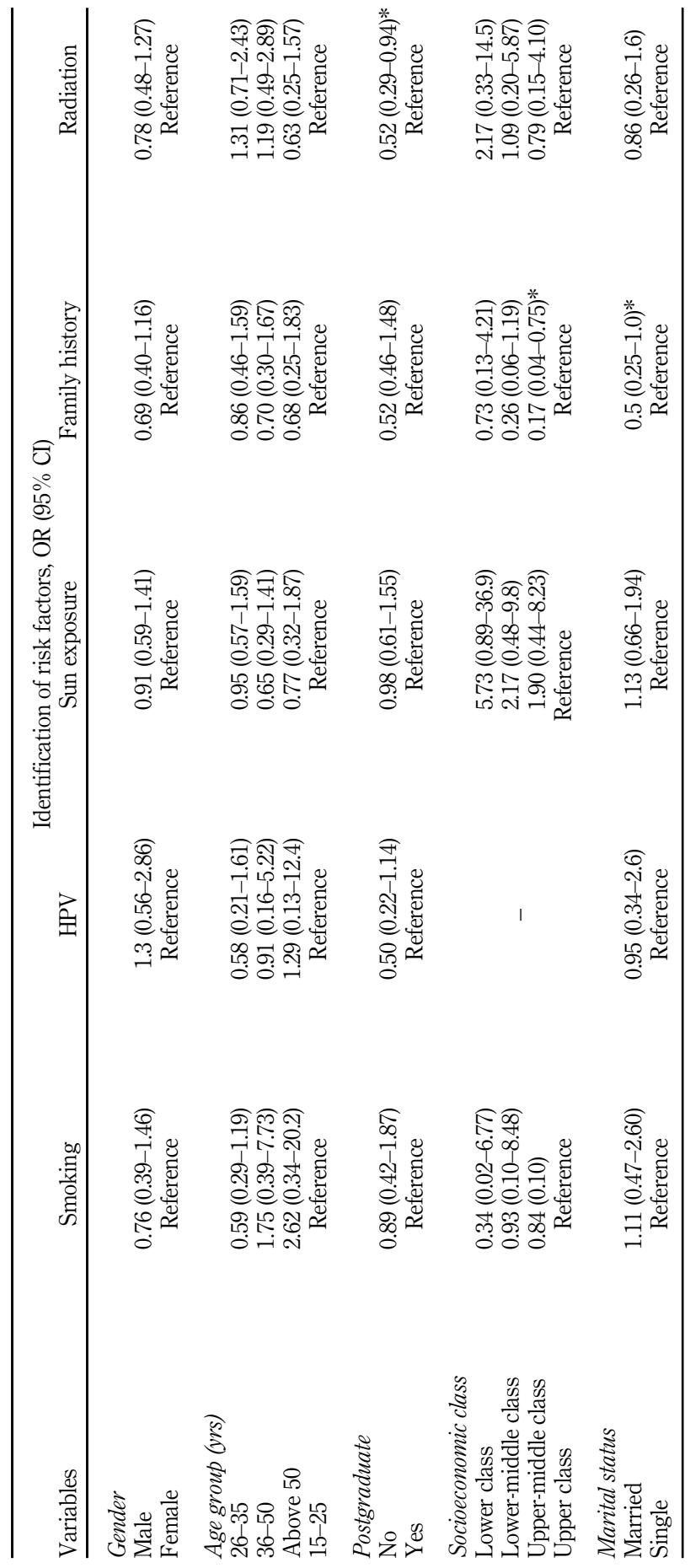

Table 3.

Identification of risk factors of head and neck cancer by sociodemographic characteristics, $(n=404)$ 
Pakistan, the incidence of HNCs has multiplied 8 to 10-fold, particularly due to unorthodox practices [10]. On account of this mounting incidence, we set out to assess the knowledge and awareness of HNCs in Karachi, the largest city of Pakistan and provincial headquarter of Sindh. Karachi has communities from all ethnic groups and has a population of 14.9 million according to the 2017 census. The study will be of interest to the medical communities to convince the government to advocate for educating the masses on the importance of prevention and to reduce the marketing of specific carcinogens.

A total of $11.6 \%$ of participants were unaware of the term "HNCs". In contrast with studies carried out in Poland and Ireland, where $14.8 \%$ and $70 \%$ of the population were unfamiliar with HNCs, our numbers were noticeably superior [11, 12]. This can be attributed to the documentation of higher risk in our geographical zone, advanced stage presentation and inadequate treatment facilities [2]. Whereas in Poland, the incidence from 1990 to 2012 decreased from $12.2 \%$ to $6.7 \%$ in males and from $2.7 \%$ to $1.8 \%$ in females, while it accounted for $2.9 \%$ of all neoplasms in Ireland $[13,14]$. In another study conducted on American Indians, over two-thirds (68\%) of the study group were incognizant of the term "HNCs" [15]. The reason for this can be justified by the overall low incidence of HNCs in the United States (US) which is $3 \%$ of all malignancies [16]. In our study, $78.7 \%$ of participants identified themselves as "not very" or "not at all" knowledgeable about HNCs; while a previous survey conducted within the US showed that $66 \%$ of the population rated their knowledge correspondingly [17]. This reflects a slightly higher conviction amongst the people of the US in comparison with the people of Pakistan despite the lower awareness in the former and can be a result of the higher literacy rate $(86 \%)$ than the latter $(55 \%)$ [18].

Our participants hailed predominantly from middle-class and educated backgrounds; however, there was a lack of knowledge about HPV as a risk factor for HNCs. Only $8.4 \%$ of the individuals identified HPV as one of the risk factors for HNC. This can be associated with limited information about HPV within our population and is further reflected in the answers to more relevant questions, as shown in the preceding text. Gillison et al. [19] reported specific risk factor profiles such as multiple sexual partners and increased oral sex practices, which aid in the transfiguration of HPV into HNC. Moreover, in a population where the literate masses harbor inadequate knowledge of HPV as a risk factor for cervical cancer, a poor association of HPV and HNCs is unsurprising [20]. Additionally, the precedence of environmental exposures triumphs against HPV as a cause for $\mathrm{HNC}$ in our region further rationalizes the knowledge sparsity [21]. Nevertheless, a retrospective case study from Italy points that there has been a significant rise of HNCs with HPV being the prime felon, advocating the need to create and cultivate awareness about HPV, along with the special promotion of its vaccinations $[22,23]$.

Only $14.3 \%(n=51)$ of the participants claimed to have heard of HPV, $7.3 \%(n=26)$ of the participants knew about the relation between HPV and throat cancer, besides cervical cancer and a mere $11.8 \%$ knew of a vaccine against HPV. This corresponds to an alarmingly low level of knowledge concerning HPV and reflects poorly on the literate participants. According to Siddiqui et al., an enormous number of children are incompletely vaccinated or not vaccinated at all in some instances in Pakistan, thus, ignorance of the HPV vaccine seems admissible [24]. Besides the low knowledge and awareness, people are brainwashed with rumors and conspiracy theories that vaccines lead to infertility and/or increasing illnesses. Demolished practices of routine HPV vaccination can also be owed to the ridiculously overpriced vaccine, the cost of which is one-third of what an average Pakistani earns in a month [25]. According to a 2006 report, betel quid and betel nut were commonly used by 34.3, $34.7 \%, 46 \%$ and $50 \%$ people of Sindh, Punjab, Pathan and Mohajir populations [26]. The fact that these are conveniently available at low prices further adds to the adversity, making it the second most used carcinogen in the subcontinent following tobacco. According to a study conducted by Khan et al., the majority of the participants acknowledged the hazardous nature
Evaluation of $\mathrm{HNC}$ knowledge 
JHR

36,4

734

of betel quid and betel nut, even though $52.4 \%$ of those participants were addicted [27]. The findings of the aforementioned study conform with our findings, showing $75 \%$ awareness of the risk of oral cancer from consumption of betel quid and betel nut, whereas our study demonstrates an awareness of $75.5 \%$ and $77.5 \%$ for betel quid and betel nut respectively. This verifies that people are aware of the consequences yet continue to use these toxoids. Perhaps the incrementing stressors of daily life, easy accessibility and intensifying competition in today's era compel people to adopt these habits as a coping mechanism.

Over three-fourths of participants in our survey identified brain cancer as a part of HNC although it has long been established that brain cancer is separate. Brain cancer has its own unique features and is dealt with by a practitioner from an entirely different field of medicine.

Interestingly, our study revealed modest levels of insight regarding the role of chronic sun exposure as a risk factor (45.8\%) and the inclusion of lip cancer in HNC (55.6\%). It is known that long-term sunlight exposure is the prime cause of lip cancer. According to a 2012 study, lip and oral cancers are the second most prevalent, diagnosed and a leading cause of death from cancer in Pakistan [28]. This deficiency can be reasoned with an overall lack of publicity in this regard; moreover, our propensity to focus only on the environmental triggers whilst dealing with $\mathrm{HNC}$ further restricts us from increasing our knowledge.

Our study showed that upper-middle class and married participants were unaware of family history as a risk factor for HNC, in contrast with the upper class and single participants. This can be attributed to the fact that the incidence of $\mathrm{HNC}$ is higher in a single population and lower socioeconomic classes, which is why they are more aware of this calamity [29]. In addition to this, married people in Pakistan have completed their education and have little correspondence with the new scientific studies, which further elaborates on the existence of low knowledge in them compared to unwedded people. Similarly, postgraduates were more informed about radiation as a risk factor than those holding lower degrees of education. Even though higher incidence and lower survival rates are observed in the less educated, they are unaware of this reality [29]. However, this finding follows a study by Naqvi et al. who reported a greater awareness of radiation exposure with a higher level of education [30].

\begin{abstract}
Limitations
Our study was limited by the presence of close-ended questions ensuing in false amplification of the pre-existing cognizance, due to suggestive answers. Secondly, HNCs are comprised of many individuals, discrete entities: each with its own distinct sign and symptom, warranting a more elaborate evaluation that our questionnaire lacked. Another drawback of our study pertains to response and cognitive bias as both self-administration of questionnaires and interviews were employed for data recruitment. The adoption of nonprobability convenience sampling led to selection bias, culminating in a high number of females, 15-25-year-olds, upper-middle socioeconomic class and educated masses. This too can amount to overestimation of awareness and knowledge. In addition to this, our small sample size of 404 people fails to uniformly incorporate every demographical subdivision.
\end{abstract}

\title{
Conclusion
}

Overall, knowledge of HNCs among the general public of Karachi is moderate. This unexceptional knowledge includes the fundamentals of HNCs and extends to recognition of common risk factors, symptoms and sub-components. However, knowledge about HPV and its role as a risk factor is low. Our study demonstrates that people indulge in detrimental habits despite having sufficient knowledge. Therefore, appropriate measures should be undertaken to increase rehabilitation centers for addicts where they are counseled to have 
pursued a healthy lifestyle. Furthermore, efforts for supplementing education campaigns on HNCs and HPV are necessary to optimize the pre-existing knowledge, detect HNCs earlier in their course and prevent future occurrences of HNC.
Evaluation of $\mathrm{HNC}$ knowledge

\section{Recommendations}

The prevailing notions of people concerning HNCs have been repeatedly demonstrated in this study; this will aid in the development of factual and legitimate awareness campaigns and educational interventions. Furthermore, these interventions will promote the prevention of primary and secondary causes of $\mathrm{HNCs}$, while simultaneously aiding in their prompt identification by means of routine screening. Adequate measures should be taken to enlighten the population regarding HPV, especially its vaccinations, as the study makes note of little knowledge in this regard among the general public. An effective and efficient approach to accomplish this is a reduction of vaccine prices. Another trend highlighted through this study is the inordinate use of alcohol, betel nut and cigarettes despite the established knowledge regarding their carcinogenic properties. Increasing the price of catastrophic addictive agents, like tobacco and alcohol, while simultaneously illegalizing betel nut and betel quid may help in controlling this adversity to some extent.

Conflict of Interest: None

\section{References}

1. Vigneswaran N, Williams MD. Epidemiologic trends in head and neck cancer and aids in diagnosis. Oral Maxillofac Surg Clin North Am. 2014; 26(2): 123-41. doi: 10.1016/j.coms.2014.01.001.

2. Bhurgri Y, Bhurgri A, Usman A, Pervez S, Kayani N, Bashir I, et al. Epidemiological review of head and neck cancers in Karachi. Asian Pac J Cancer Prev. 2006; 7(2): 195-200.

3. Bhurgri Y. Cancer of the oral cavity - trends in Karachi South (1995-2002). Asian Pac J Cancer Prev. 2005; 6(1): 22-6.

4. Akhtar A, Hussain I, Talha M, Shakeel M, Faisal M, Ameen M, et al. Prevalence and diagnostic of head and neck cancer in Pakistan. Pak J Pharm Sci. 2016; 29(5 Suppl): 1839-46.

5. Herrero JI, Pardo F, D'Avola D, Alegre F, Rotellar F, Iñarrairaegui M, et al. Risk factors of lung, head and neck, esophageal, and kidney and urinary tract carcinomas after liver transplantation: the effect of smoking withdrawal. Liver Transpl. 2011; 17(4): 402-8. doi: 10. 1002/lt.22247.

6. Brockstein B, Haraf DJ, Rademaker AW, Kies MS, Stenson KM, Rosen F, et al. Patterns of failure, prognostic factors and survival in locoregionally advanced head and neck cancer treated with concomitant chemoradiotherapy: a 9-year, 337-patient, multi-institutional experience. Ann Oncol. 2004; 15(8): 1179-86. doi: 10.1093/annonc/mdh308.

7. Sankaranarayanan R, Ramadas K, Thara S, Muwonge R, Thomas G, Anju G, et al. Long term effect of visual screening on oral cancer incidence and mortality in a randomized trial in Kerala, India. Oral Oncol. 2013; 49(4): 314-21. doi: 10.1016/j.oraloncology.2012.11.004.

8. Mackay J, Jemal A, Lee N, Parkin D, (Eds). The cancer atlas. Atlanta, GA: American Cancer Society; 2006.

9. Bhurgri Y, Bhurgri A, Nishter S, Ahmed A, Usman A, Pervez S, et al. Pakistan-country profile of cancer and cancer control 1995-2004. J Pak Med Assoc. 2006; 56(3): 124-30.

10. Merchant A, Husain SS, Hosain M, Fikree FF, Pitiphat W, Siddiqui AR, et al. Paan without tobacco: an independent risk factor for oral cancer. Int J Cancer. 2000; 86(1): 128-31.

11. O'Connor TE, Papanikolaou V, Keogh IJ. Public knowledge of head and neck cancer. Ir Med J. 2010; 103(4): 105-7. 
JHR

36,4

12. Krentowska A, Sierko-Nobis E, Strzalka A, Pietruszewska W, Hempel D, Sierko E. Awareness of head and neck cancer - a multicentre survey among young respondents in Poland. Int Dent J. 2018; 68(6): 441-9. doi: 10.1111/idj.12402.

13. Gawełko J, Cierpiał-Wolan M, Kawecki A, Wilk K, Pięciak-Kotlarz DB, Sikorski D. Comparative analysis of the incidence of head and neck cancer in south-eastern Poland and in Poland in the years 1990-2012. Contemp Oncol (Pozn). 2017; 21(1): 77-82. doi: 10.5114/wo.2017.66497.

14. Ireland, National Cancer Registry. New trends and reports of head and neck cancer. [cited 2014 October 1]. Available at: https://www.ncri.ie/news/article/new-trends-report-head-neck-cancerpublished.

15. Ferlay J, Colombet M, Soerjomataram I, Mathers C, Parkin DM, Piñeros M, et al. Estimating the global cancer incidence and mortality in 2018: GLOBOCAN sources and methods. Int J Cancer. 2019; 144(8): 1941-53. doi: 10.1002/ijc.31937.

16. Dwojak S, Deschler D, Sargent M, Emerick K, Guadagnolo BA, Petereit D. Knowledge and screening of head and neck cancer among American Indians in South Dakota. Am J Public Health. 2015; 105(6): 1155-60. doi: 10.2105/AJPH.2014.302177.

17. Siegel RL, Miller KD, Jemal A. Cancer statistics. CA Cancer J Clin. 2019; 69(1): 7-34. doi: 10.3322/ caac.21551.

18. Luryi AL, Yarbrough WG, Niccolai LM, Roser S, Reed SG, Nathan CA, et al. Public awareness of head and neck cancers: a cross-sectional survey. JAMA Otolaryngol Head Neck Surg. 2014; 140(7): 639-46. doi: 10.1001/jamaoto.2014.867.

19. World Atlas. List of countries by literacy rate. [cited 2019 August 6]. Available at: https://www. worldatlas.com/articles/the-highest-literacy-rates-in-the-world.html.

20. Gillison ML, D'Souza G, Westra W, Sugar E, Xiao W, Begum S, et al. Distinct risk factor profiles for human papillomavirus type 16-positive and human papillomavirus type 16-negative head and neck cancers. J Natl Cancer Inst. 2008; 100(6): 407-20. doi: 10.1093/jnci/djn025.

21. Zaheer R, Alam N, Faqir Hussain KC, Herekar AA, Nasir H, Bhutta SZ. Awareness about human papillomavirus as a cause of cervical cancer and its prevention in the undergraduate female students of Karachi. J Pak Med Assoc. 2017; 67(1): 27-32.

22. Schroeder L, Boscolo-Rizzo P, Dal Cin E, Romeo S, Baboci L, Dyckhoff G, et al. Human papillomavirus as prognostic marker with rising prevalence in neck squamous cell carcinoma of unknown primary: a retrospective multicentre study. Eur J Cancer. 2017; 74: 73-81. doi: 10.1016/j. ejca.2016.12.020.

23. Bossi P, Orlandi E, Miceli R, Perrone F, Guzzo M, Mariani L, et al. Treatment-related outcome of oropharyngeal cancer patients differentiated by HPV dictated risk profile: a tertiary cancer centre series analysis. Ann Oncol. 2014; 25(3): 694-9. doi: 10.1093/annonc/mdu004.

24. Siddiqui S, Akbar M, Mehtab A, Zafar M, Shahid S, Ahmed S, et al. Frequency of immunisation of children upto five years of age according to vaccination card in Karachi - a multicentre study. Ann Abbasi Shaheed Hosp Karachi Med Dent Coll. 2017; 22(1): 12-9.

25. CEIC. Pakistan Average monthly wages: by industry. [cited 2016 January 5]. Available at: https:// www.ceicdata.com/en/pakistan/average-monthly-wages-by-industry?page $=3$.

26. Mazahir S, Malik R, Maqsood M, Merchant KA, Malik F, Majeed A, et al. Socio-demographic correlates of betel, areca and smokeless tobacco use as a high risk behavior for head and neck cancers in a squatter settlement of Karachi, Pakistan. Subst Abuse Treat Prev Policy. 2006; 1(1): 10. doi: 10.1186/1747-597X-1-10.

27. Khan MS, Bawany FI, Shah SR, Hussain M, Arshad MH, Nisar N. Comparison of knowledge, attitude and practices of betelnut users in two socio-economic areas of Karachi. J Pak Med Assoc. 2013; 63(10): 1319-25.

28. Sarwar MR, Saqib A. Cancer prevalence, incidence and mortality rates in Pakistan in 2012. Cogent Med. 2017; 4(1): 1288773. doi: 10.1080/2331205X.2017.1288773. 
29. Johnson S, McDonald JT, Corsten MJ. Socioeconomic factors in head and neck cancer. J Otolaryngol Head Neck Surg. 2008; 37(4): 597-601.

30. Naqvi STS, Batool SW, Rizvi SAH, Farhan K. Awareness of hazards of X-ray imaging and perception regarding necessary safety measures to be taken during X-ray imaging procedures among patients in public sector tertiary hospitals of Karachi, Pakistan. Cureus. 2019; 11(5): e4756. doi: $10.7759 /$ cureus.4756.

Evaluation of $\mathrm{HNC}$ knowledge

Corresponding author

Zainab Mohsin can be contacted at: Zainabmj39@gmail.com

For instructions on how to order reprints of this article, please visit our website:

www.emeraldgrouppublishing.com/licensing/reprints.htm

Or contact us for further details: permissions@emeraldinsight.com 